\title{
Computed tomography guided tailored approach to transfemoral access in patients undergoing transcatheter aortic valve implantation
}

\author{
Łukasz Wiewiórka ${ }^{1}$, Jarosław Trębacz ${ }^{1}$, Robert Sobczyński ${ }^{2}$, Maciej Stąpór ${ }^{1}$, \\ Elżbieta Ostrowska-Kaim ${ }^{1}$, Janusz Konstanty-Kalandyk ${ }^{2}$, Robert Musiał ${ }^{3}$, \\ Andrzej Gackowski ${ }^{4}$, Krzysztof Malinowski ${ }^{5}$, Paweł Kleczyński ${ }^{1}$, \\ Krzysztof Żmudka ${ }^{1}$, Bogusław Kapelak ${ }^{2}$, Jacek Legutko ${ }^{1}$ \\ ${ }^{1}$ Jagiellonian University Medical College, Faculty of Medicine, Institute of Cardiology, \\ Department of Interventional Cardiology, John Paul II Hospital, Krakow, Poland \\ ${ }^{2}$ Jagiellonian University Medical College, Faculty of Medicine, Institute of Cardiology, \\ Department of Cardiac Surgery and Transplantation, John Paul II Hospital, Krakow, Poland \\ ${ }^{3}$ Department of Anesthesiology and Intensive Therapy, John Paul II Hospital, Krakow, Poland \\ ${ }^{4}$ Jagiellonian University Medical College, Faculty of Medicine, Institute of Cardiology, \\ Department of Coronary Artery Diseases, John Paul II Hospital, Krakow, Poland \\ ${ }^{5} 2^{\text {nd }}$ Department of Cardiology, Jagiellonian University Medical College, Krakow, Poland
}

\begin{abstract}
Background: Transfemoral approach (TFA) is the most common access route for transcatheter aortic valve implantation (TAVI). Percutaneous femoral access (PA) is preferred over the surgical approach (SA), however, may be associated with a higher risk of access site complications. Thus, we aimed to assess outcomes of computed tomography-guided tailored approach to percutaneous and surgical TFA in patients undergoing TAVI.

Methods: We evaluated data of 158 patients, who underwent TAVI via femoral route between January 2017 and December 2018. In the PA group, vascular closure was performed with the use of two percutaneous suture devices and an additional mechanical seal device. We compared complications rate and outcomes.

Results: Of the 158 patients (92\%; mean age 79.6 years, 60.8\% female), in 92 (61\%) patients PA was performed and in 66 (39\%) patients $S A$ was used. Median (interquartile range) radiation exposure as well as contrast volume dose was higher in the PA group compared to the SA group 614.0 (410.0; 1104.0) $m G y$ vs. 405 (240.5; 658.0) $m G y(p<0.001)$ and 150.0 (120.0; 180.7) $m L$ vs. 130.0 (100.0; 160.0) $m L(p=0.04)$, respectively. Bleeding complications were similar in the PA group $11(12.2 \%)$ compared to $5(8.62 \%)$ in the $S A$ group $(p=0.48)$. Median length of hospital stay was also similar in the PA and the SA group 6.00 (5.00; 8.00) days vs. 6.00 (4.00; 8.00) days, respectively $(p=0.31)$.

Conclusions: Computed tomography-guided PA in TAVI may provide comparable procedural outcomes compared to the $S A$, despite a higher radiation dose and the use of contrast dye, while being less invasive. (Cardiol J 2023; 30, 1: 51-58)
\end{abstract}

Key words: aortic stenosis, outcomes, transcatheter aortic valve implantation, vascular access, vascular closure devices

Address for correspondence: Łukasz Wiewiórka, MD, Department of Interventional Cardiology, Jagiellonian University Medical College and the John Paul II Hospital, ul. Prądnicka 80, 31-202 Kraków, Poland, tel: + 48509099317 , email:drlucwie@gmail.com

Received: 29.10.2020 Accepted: 5.05.2021 Early publication date: 21.05.2021

This article is available in open access under Creative Common Attribution-Non-Commercial-No Derivatives 4.0 International (CC BY-NC-ND 4.0) license, allowing to download articles and share them with others as long as they credit the authors and the publisher, but without permission to change them in any way or use them commercially. 


\section{Introduction}

Transcatheter aortic valve implantation (TAVI) has emerged as a favorable alternative to conventional surgical aortic valve surgery, for high-risk patients presenting severe aortic stenosis [1]. Over the years, several approaches have been introduced such as: transfemoral, transapical, subclavian, direct aortic, transcaval or even via carotid artery $[2,3]$. However, the transfemoral approach remains the most favorable access with superior outcomes compared to other access routes $[4,5]$. Initially, access to femoral artery was obtained with a surgical cut down in most cases, yet, due to its disadvantages such as the need of general anesthesia, the duration of the procedure and longer recovery time, there was an increasing need for the development of a less invasive access that could successfully overcome those drawbacks and follow the minimalist approach [5]. Moreover, a fully percutaneous closure of the femoral artery with vascular closure devices (VCD) is associated with less pain, faster hemostasis, mobilization, and quicker hospital discharge when compared with the surgical cut down [6]. Currently, there are several VCD systems available for large vessels - Prostar XL (Abbott, USA), Perclose Proglide (Abbott, USA), Manta (Teleflex, USA) and Angio-Seal (Abbott, USA) [7-12]. In our study, we aimed to investigate procedural outcomes and complications rate between percutaneous access (PA) with the use of two percutaneous suture devices combined with one mechanical seal device and surgical access (SA).

\section{Methods}

Our study was a single center, prospective registry in which consecutive patients, who underwent TAVI between January 1, 2017 and December 31, 2018, were included. All patients were scheduled for TAVI by the Heart Team based on clinical indications and following multidisciplinary evaluation. All procedures were performed by an interventional cardiologist and cardiac surgeon, acting as a team. The choice between PA and SA as well as the left or right femoral artery access was left to the operators' discretion, based on a computed tomography (CT) and cardiologist's and surgeon's consensus. Images from CT were evaluated for optimal access type and puncture site in terms of calcifications distribution within femoral and iliac arteries as well as their anatomic course. Percutaneous access was obtained after cross-over angiography performed with a pigtail catheter, to determine the optimal puncture site with subsequent $6 \mathrm{Fr}$ sheath introduction followed by two Proglides insertion and an 8 Fr sheath. Finally, a delivery sheath was inserted. In both groups, unfractionated heparin was administrated with control activated clotting time between 250-300 s. TAVI procedure was performed typically under analgosedation. For arterial closure, two Proglide devices with additional 8 Fr Angio-Seal were used in the PA group, after the administration of $50 \mathrm{mg}$ protamine sulphate. Cross-over angiography was also performed at the end of the procedure to exclude bleeding. In the PA direct left ventricle wire pacing was the dominant method of pacing without access to venous system [13, 14]. Surgical access for TAVI required a transverse exposure of the common femoral artery. The procedure was performed in local anesthesia. It began with a skin incision as small as possible to minimize the wound size and further complications. The surgeon exposed the artery with subsequent puncture of the artery and insertion of 6 Fr sheath, followed by an exchange for a delivery sheath over the stiff wire. For the closure of the femoral artery, a suture was used with a subsequent contralateral contrast safety injection. Additional contralateral arterial and/or venous access sites were also closed with 6 Fr Angio-Seal devices in both groups.

Baseline clinical and echocardiographic characteristics, together with frailty evaluation by the Canadian Study of Health and Aging scale (CSHA) and procedural data were assessed [15]. Peri- and postprocedural complications, including bleeding, were assessed according to The Valve Academic Research Consortium endpoint definitions (VARC-2) criteria [16]. Finally, clinical outcomes at 30 days were assessed. The study was approved by the institutional ethics board.

\section{Statistical analysis}

Categorical variables are presented as numbers and percentages and were analyzed with the Pearson $\chi^{2}$ or Fisher exact test. Continuous variables are expressed as a mean \pm standard deviation (SD) for normally distributed variables and a median with quartiles for non-normally distributed variables. The normality of the data was assessed using the Shapiro-Wilk test. The groups were compared using the Student t-test for normally distributed continuous variables and the Mann-Whitney U test for non-normally distributed continuous variables. P-values $<0.05$ were considered statistically significant. All statistical 
Table 1. Characteristics of patients in the percutaneous and surgical access groups.

\begin{tabular}{|c|c|c|c|c|}
\hline & $\begin{array}{l}\text { Surgical access } \\
\qquad(n=66)\end{array}$ & $\begin{array}{l}\text { Percutaneous } \\
\text { access }(n=92)\end{array}$ & $\begin{array}{c}\text { Total } \\
(\mathrm{n}=158)\end{array}$ & $\mathbf{P}$ \\
\hline Age [years], mean $\pm \mathrm{SD}$ & $78.7 \pm 10.1$ & $80.3 \pm 7.01$ & $79.6 \pm 8.43$ & 0.27 \\
\hline Weight $[\mathrm{kg}]$, median (IQR) & $70.00(62.00 ; 81.50)$ & $70.00(62.00 ; 80.00)$ & $70.00(62.00 ; 80.00)$ & 0.93 \\
\hline BMI $\left[\mathrm{kg} / \mathrm{m}^{2}\right]$, median (IQR) & $28.30(24.78 ; 30.75)$ & $28.00(25.20 ; 31.45)$ & $28.20(25.00 ; 31.20)$ & 0.62 \\
\hline Male & $29(43.94 \%)$ & $33(35.87 \%)$ & $62(39.24 \%)$ & 0.30 \\
\hline Diabetes melitus & $20(30.77 \%)$ & $35(39.33 \%)$ & $55(35.71 \%)$ & 0.34 \\
\hline Atrial fibrilation & $23(35.94 \%)$ & $38(42.70 \%)$ & $61(39.87 \%)$ & 0.39 \\
\hline Hypertension & $62(95.38 \%)$ & $86(95.56 \%)$ & $148(95.48 \%)$ & 1.00 \\
\hline Dialisys & $1(1.56 \%)$ & $2(2.22 \%)$ & $3(1.95 \%)$ & 1.00 \\
\hline $\mathrm{GFR}[\mathrm{ml} / \mathrm{min}]$, mean $\pm \mathrm{SD}$ & $58.97 \pm 19.11$ & $56.64 \pm 19.69$ & $57.63 \pm 19.42$ & 0.46 \\
\hline Creatynine $[\mathrm{mmol} / \mathrm{L}]$, median (IQR) & $90(76.00 ; 109.00)$ & $91.00(78.00 ; 119.00)$ & $91.00(77.00 ; 114.50)$ & 0.36 \\
\hline Hemoglobin $[\mathrm{g} / \mathrm{dL}]$, mean $\pm \mathrm{SD}$ & $11.92 \pm 1.73$ & $11.92 \pm 1.80$ & $11.63 \pm 1.76$ & 0.75 \\
\hline EuroSCORE standard & $8.83 \pm 2.77$ & $8.98 \pm 2.50$ & $8.92 \pm 2.61$ & 0.74 \\
\hline Logistic EuroSCORE [\%] & $15.9 \pm 12.7$ & $16.1 \pm 14.1$ & $16.0 \pm 13.5$ & 0.93 \\
\hline EuroSCORE 2 [\%] & $4.12 \pm 3.15$ & $4.10 \pm 3.32$ & $4.11 \pm 3.22$ & 0.97 \\
\hline STS [\%] & $4.45 \pm 2.51$ & $4.56 \pm 3.37$ & $4.50 \pm 2.97$ & 0.85 \\
\hline DAPT & $16(24.24 \%)$ & $18(19.56 \%)$ & $34(21.52 \%)$ & 0.39 \\
\hline Ejection fraction [\%], median (IQR) & $60.00(55.00 ; 65.00)$ & $60.00(50.00 ; 65.00)$ & $60.00(50.00 ; 65.00)$ & 0.19 \\
\hline AVA $\left[\mathrm{cm}^{2}\right]$, median (IQR) & $0.80(0.60 ; 0.90)$ & $0.70(0.60 ; 0.90)$ & $0.80(0.60 ; 0.90)$ & 0.55 \\
\hline AVMG [mmHg], median (IQR) & $45.00(38.00 ; 55.00)$ & $47.00(36.75 ; 55.25)$ & $46.00(37.50 ; 55.00)$ & 0.84 \\
\hline AVPG [mmHg], median (IOR) & $70.00(60.75 ; 94.00)$ & $76.00(63.00 ; 91.00)$ & $73.00(62.00 ; 91.00)$ & 0.41 \\
\hline
\end{tabular}

AVA - aortic valve area; AVMG - aortic valve mean gradient; AVPG - aortic valve peak gradient; BMI — body mass index; DAPT — dual antiplatelet therapy: EuroSCORE - European System for Cardiac Operative Risk Evaluation; GFR - glomerular filtration rate; IQR — interquartile range; SD — standard deviation; STS - Society of Thoracic Surgeons

analyses were performed using the $\mathrm{JMP}^{\circledR}$ Version 15 (SAS Institute Inc., Cary, NC, USA).

\section{Results}

The femoral approach was used in 158 patients (mean age $79.6 \pm 8.43$ years; $59 \%$ females). The PA group consisted of 92 patients $(58.2 \%$; $64.1 \%$ females). The baseline clinical characteristics was similar between both groups (Table 1). Patients in the PA group were considered less frail compared to the SA group (Fig. 1).

Procedural data are presented in Table 2. The radiation dose was significantly higher in the $\mathrm{PA}$ group compared to the SA group (614.0 [410.0 -1104.0) mGy vs. 405.0 [240.5-658.0] mGy; p < $<0.001$ ), while the duration of radiation was only slightly higher in the PA group $(20.7$ [16.0; 26.5] $\min$ vs. 19.0 [13.9; 22.9] $\mathrm{min}, \mathrm{p}=0.09$ ). The amount of contrast used was also higher in the PA group $(154.7 \pm 50.6 \mathrm{~mL}$ vs. $138.9 \pm 69.2 \mathrm{~mL}, \mathrm{p}=0.04)$.

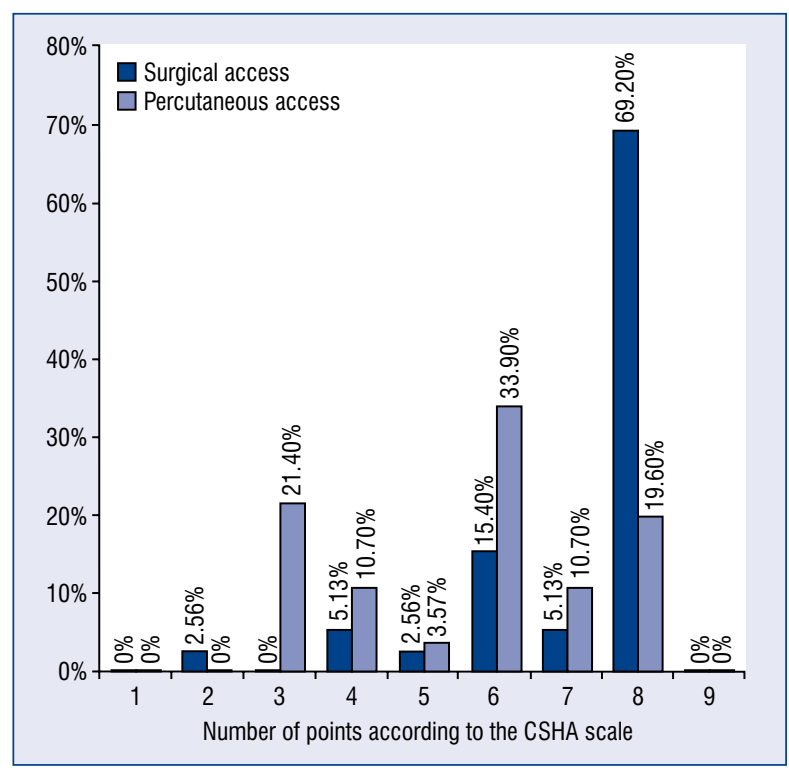

Figure 1. Percentage values of patient`s scores according to Clinical Frailty Syndrome CSHA Scale (Canadian Study of Health and Aging scale [CSHA]) $(p<0.001)$. 
Table 2. Procedural data.

\begin{tabular}{|c|c|c|c|c|}
\hline & $\begin{array}{c}\text { Total } \\
(\mathrm{n}=158)\end{array}$ & $\begin{array}{l}\text { Surgical access } \\
\qquad(n=66)\end{array}$ & $\begin{array}{l}\text { Percutaneous access } \\
\text { ( } \mathrm{n}=92)\end{array}$ & $\mathbf{P}$ \\
\hline Self-expandable valve & $124(82.7 \%)$ & $47(75.8 \%)$ & $77(87.5 \%)$ & 0.03 \\
\hline Ballon-expandable valve & $22(14.7 \%)$ & $11(17.7 \%)$ & $11(12.5 \%)$ & 0.03 \\
\hline Direct left ventricular wire pacing & $87(55.06 \%)$ & $26(39.39 \%)$ & $61(66.30 \%)$ & 0.003 \\
\hline $\begin{array}{l}\text { Procedure time [min], } \\
\text { median (IQR) }\end{array}$ & $\begin{array}{c}80.00 \\
(70.00 ; 95.00)\end{array}$ & $\begin{array}{c}85.00 \\
(70.00 ; 95.00)\end{array}$ & $\begin{array}{c}80.00 \\
(70.00 ; 95.00)\end{array}$ & 0.37 \\
\hline $\begin{array}{l}\text { Radiation dose [mGy], } \\
\text { median (IQR) }\end{array}$ & $\begin{array}{c}513.00 \\
(325.50 ; 929.00)\end{array}$ & $\begin{array}{c}405.00 \\
(240.50 ; 658.00)\end{array}$ & $\begin{array}{c}614.00 \\
(410.00 ; 1104.00)\end{array}$ & $<0.001$ \\
\hline $\begin{array}{l}\text { Contrast dose }[\mathrm{mL}] \\
\text { median (IQR) }\end{array}$ & $\begin{array}{c}150.00 \\
(100.00 ; 174.50)\end{array}$ & $\begin{array}{c}130.00 \\
(100.00 ; 160.00)\end{array}$ & $\begin{array}{c}150.00 \\
(120.00 ; 180.75)\end{array}$ & 0.04 \\
\hline VARC-2 bleeding complications & $16(10.88 \%)$ & $5(8.62 \%)$ & $11(12.36 \%)$ & 0.48 \\
\hline Life-threatening & $4(25 \%)$ & $2(40 \%)$ & $2(18.18 \%)$ & \\
\hline Major & $6(37.50 \%)$ & $2(40 \%)$ & $4(36.36 \%)$ & \\
\hline Minor & $6(37.50 \%)$ & $1(10 \%)$ & $5(45.45 \%)$ & \\
\hline \multicolumn{5}{|l|}{ Lowest hospitalization } \\
\hline Hemoglobin $[\mathrm{g} / \mathrm{dL}]$, median IQR & $10.00(9.00 ; 11.15)$ & $9.90(9.20 ; 11.05)$ & $10.00(8.80 ; 11.40)$ & 0.71 \\
\hline Blood transfusion & $20(13.25 \%)$ & $5(8.06 \%)$ & $15(16.85 \%)$ & 0.12 \\
\hline $\begin{array}{l}\text { Hospitalization time [day], } \\
\text { median (IQR) }\end{array}$ & $6.00(5.00 ; 8.00)$ & $6.00(5.00 ; 8.00)$ & $6.00(4.00 ; 8.00)$ & 0.31 \\
\hline
\end{tabular}

IQR - interquartile range; VARC — Valve Academic Research Consortium

In the PA group, direct left ventricle wire pacing was performed in $66.3 \%$ compared to the SA group only $39.4 \%(\mathrm{p}=0.003)$. Bleeding complications after index procedure occurred in 11 patients in the PA group and in 5 patients in the SA group ( $12.4 \%$ vs. $8.6 \%, \mathrm{p}=0.48)$. In both groups, most bleeding complications were associated with the access site. There was 1 case of cardiac tamponade in each group, related to an aortic ring rupture. Three bleeding events were associated with periprocedural blood loss, $2(2.2 \%)$ in PA and $1(1.5 \%)$ in the SA group. Eight $(8.7 \%)$ episodes of bleeding in the PA group were related with the access site, $3(3.3 \%)$ of them were associated with access for control angiography. Respectively, there were $3(4.8 \%)$ bleeding episodes in SA group, while $1(1.5 \%)$ of them was associated with access for control angiography. There were 2 cases of lifethreatening bleeding in both groups $(2.2 \%$ of the PA group and $3.0 \%$ of the SA group, $p=0.06$ ), 4 cases of major bleeding in the PA group (4.3\%) and 2 in the SA group (3.0\%), $\mathrm{p}=0.06$, and 5 cases of minor bleeding in the PA group (5.4\%) and 1 in the SA group (1.5\%), $\mathrm{p}=0.06$. The groups of patients did not differ in terms of the lowest median of blood hemoglobin level $9.9 \mathrm{~g} / \mathrm{dL}(9.2-11.1)$ vs. $10.0 \mathrm{~g} / \mathrm{dL}(8.8 ; 11.4), \mathrm{p}=0.71$. The transfusion of packed red blood cells occurred more frequently in the PA group (15 cases, 16.8\%) than in the SA group (5 cases, $8.1 \%$ ), but it was not statistically significant $(\mathrm{p}=0.12)$. An ischemic stroke occurred in 4 patients in the PA group (4.3\%) and 2 cases were qualified as major and minor strokes $(2.2 \%$ each). In the SA group, there was no case of stroke; however, the difference between the groups was not significant $(\mathrm{p}=0.45)$. All of the complications are presented in Table 3. There was no statistical difference in need for the use of dual antiplatelet therapy $19.6 \%$ in PA and $24.2 \% \mathrm{SA}, \mathrm{p}=0.39$ or triple antiplatelet therapy $3.0 \%$ PA vs. $2.2 \%$ $\mathrm{SA}, \mathrm{p}=1.00$. After 1 month of follow-up, there was only 1 case of minor access site bleeding as a result of local hematoma, which did not require a blood transfusion. No cases of death or need for re-hospitalization were reported.

\section{Discussion}

Transcatheter aortic valve implantation via transfemoral approach is an established valuable treatment option for high-risk surgical patients; however, bleeding related to the smaller sheath size and other vascular complications remain relevant concerns $[9,12]$. Furthermore, those complications have been reported to be quite frequent and may be associated with poor clinical outcomes, such as increased morbidity in the form of acute kidney injury and increased mortality 
Table 3. Major periprocedural complications.

\begin{tabular}{lcccc}
\hline & $\begin{array}{c}\text { Total } \\
\text { (n = 158) }\end{array}$ & $\begin{array}{c}\text { Surgical access } \\
\text { (n = 66) }\end{array}$ & $\begin{array}{c}\text { Percutaneous access } \\
\text { (n = 92) }\end{array}$ & P \\
\hline Valve displacement & $1(0.6 \%)$ & $0(0.0 \%)$ & $1(1.1 \%)$ & 0.29 \\
Second valve, bailout & $4(2.5 \%)$ & $2(3 \%)$ & $2(2.2 \%)$ & 0.64 \\
AVB requiring PM* & $18(11.8 \%)$ & $9(13.6 \%)$ & $9(9.8 \%)$ & 0.75 \\
Cardiogenic shock & $5(3.2 \%)$ & $1(1.5 \%)$ & $4(4.3 \%)$ & 0.41 \\
Conversion to surgery & $0(0.0 \%)$ & $0(0.0 \%)$ & $0(0.0 \%)$ & $N A$ \\
Cardiac tamponade & $2(1.3 \%)$ & $1(1.5 \%)$ & $1(1.1 \%)$ & 0.85 \\
Acute renal failure & $1(0.6 \%)$ & $0(0.0 \%)$ & $1(1.1 \%)$ & 0.54 \\
Myocardial infarction & $1(0.6 \%)$ & $1(1.5 \%)$ & $0(0.0 \%)$ & 0.60 \\
Stroke & $4(2.5 \%)$ & $0(0.0 \%)$ & $4(4.3 \%)$ & 0.42 \\
Death* & $2(1.3 \%)$ & $1(1.5 \%)$ & $1(1.1 \%)$ & 0.85 \\
\hline
\end{tabular}

Data are presented as number and percentage. *During in-hospital stay. AVB — atrioventricular block; NA — not applicable; PM — pacemaker

$[9,16]$. Our study showed that the most common complications in the transfemoral approach for TAVI were bleeding events related to vascular access. Their incidence was similar in both groups, despite PA group being less frail, what impacts outcomes crucially [17]. These results were in line with similar studies directly comparing full percutaneous technique with surgical puncture and closure [18]. Moreover, observations herein, support the idea of teamwork between interventional cardiologist and cardiac surgeon and their consensus about the type of vascular access tailored by the CT assessment. However, the present results are contrary to the findings by Walas et al. [16], who compared vascular access site complications between the two approaches in a large group of patients and reported higher risks of all vascular complications in the PA group and highlighting SA as a safer option. On the other hand, the patients included in the two arms of that study were not identical in terms of body mass index (BMI) and comorbidities, which may have strongly affected the results. In the current study, no statistically significant differences were found in BMI, kidney function, hypertension, diabetes and preprocedural hemoglobin between the study groups. Also, regarding the need for dual - and triple antiplatelet therapy no statistical differences were found that may have had an impact on bleeding complications. As previously mentioned, there are three main VCD systems currently available. A comparison between Proglide and Prostar revealed a higher incidence of major vascular complications or in-hospital mortality in the Prostar group [10]. It also appears that the recently introduced collagen plug-based Manta device in Europe, is characterized by higher rates of vascular complications and non-significantly higher rates of urgent or subacute vascular surgery or other endovascular surgery [9]. All these findings highlighted that Proglide may be comparable to the outcomes of the surgical approach.

Nowadays, we observe a trend towards minimalization the complexity of the TAVI procedure. Direct left ventricular wire pacing is a handy tool because it does not require additional venous access $[13,14]$. Even though, in the present study, direct left ventricle pacing was significantly more frequent in PA, a beneficial effect was not observed on the reduction of bleeding complications in this group. What was different in the current study, to achieve hemostasis in the PA group, two Proglides with additional Angio-Seal and administration of protamine sulphate were used. An appropriate dose adjusted to the heparin dose was administered at the end of the procedure to reverse unfractionated heparin and achieve potential benefits in reducing bleeding complications [19]. The present study showed a lower incidence of all bleeding complications ( $12.2 \%$ vs. $28.6 \%$ ) associated with the access site in the PA with additional Angio-Seal compared to closure with two Proglides solely, but still with a higher incidence than in the SA group [20-22]. These results may be influenced by the study team design, which consisted of an interventional cardiologist and a cardiac surgeon with extensive vascular experience. Each choice between access type, was preceded by a detailed analysis of the calcification distribution in CT (Fig. 2). The length of the calcified plaques along the axis of the vessel played a major role in choosing the most appropriate approach. A long section 


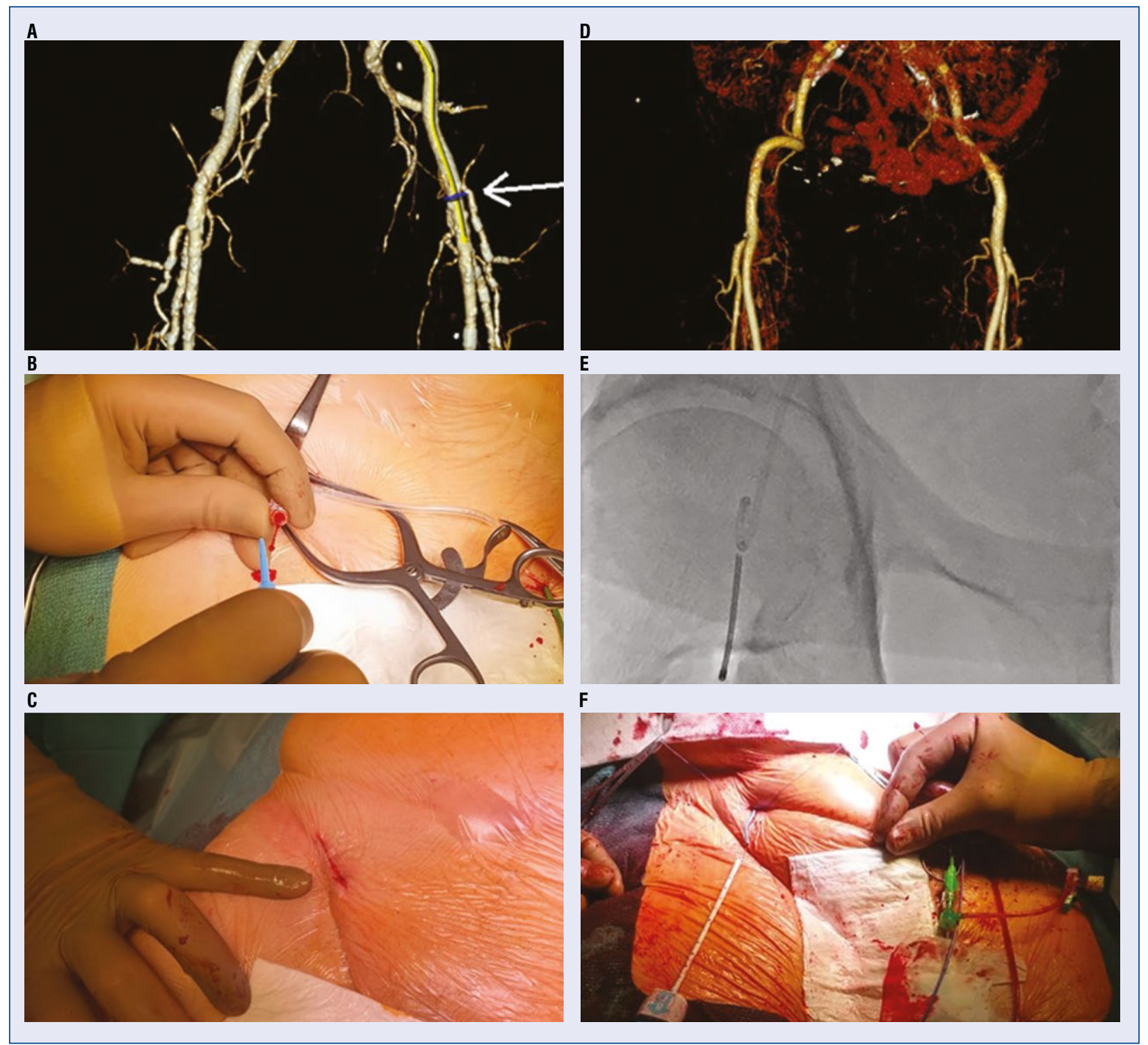

Figure 2. Step by step obtaining vascular access in the surgical and percutaneous groups; A. Surgical access femoral artery with long, extensive atherosclerotic plaques; B. Surgical access - femoral artery puncture; C. Surgical femoral artery closure; D. Percutaneus access - femoral artery with point atherosclerotic plaques; E. Percutaneous access - femoral artery puncture; F. Vascular closure devices in percutaneous access — two Proglides with additional Angio-Seal.

of the artery covered by atherosclerotic plaques with calcifications is associated with more problematic hemostasis achievement, when using the VCDs (Fig. 2). Patients with a CT scan revealing extensive calcifications of the common femoral artery, were referred to the SA approach. Bulky or circumferential calcification in the femoral artery may cause an inability of a proper automated mechanical suture deployment which may be followed by bleeding. In our opinion, a proper qualification of patients with extensive, long calcified atherosclerotic plaques for the SA seems to be crucial in reducing bleeding complications in TAVI. In the present study a trend towards shorter hospital stay in the PA group was not noted. Nevertheless, the fact that in the PA group blood transfusions were more frequent, and could also have had the effect of extending hospital stay. Early discharge has not only been a subject of numerous studies [23-27] but has also been reported to improve the outcomes and quality of life after the interventional procedures [25]. Aldalati et al. [26] demonstrated significant reduction in the hospital stay duration in cases with VCD. In their study, early discharge 
was observed in $71 \%$ of patients with transfemoral PA approach vs. $22 \%$ observed in patients with the SA. Furthermore, PA has been reported to be associated with shortened hospital stay and lower post-procedural complications and major adverse cardiac and cerebrovascular events [28]. Other studies have reported that the transfemoral approach, in general, is an independent factor for early discharge [27].

In a study by Giordano el al. [29] compared acute and 1-month outcomes of patients undergoing TAVI using as VCD either Proglide or Prostar during TAVI. Despite similar device success rates, Prostar was associated with a lower risk of vascular stenosis, but a higher rate of device malfunction. Unadjusted analysis for 1-month outcomes suggested higher rates of major adverse events, any bleeding, major bleeding, and renal failure in patients receiving Prostar. However, propensity score-adjusted analysis did not confirm any significant differences, suggesting that confounding factors mostly drove unadjusted differences. They concluded that the use of Proglide and Prostar as VCD of choice for TAVI appears similarly safe and effective, despite some potential benefits associated with Proglide.

The risk of failure or closure of devices and of consequent complications can also be estimated using CT. Currently, available studies have reported a higher incidence of failure in cases of circumferential calcification of the vessel wall, which involves more than $90^{\circ}$ and distance of $>80 \mathrm{~mm}$ between the skin surface and common femoral artery measured at an optimal angle of $45^{\circ}$ for puncture [30]. These findings in combination with a high score in clinical frailty syndrome may help determine good candidates for conventional surgical femoral access during TAVI.

\section{Limitations of the study}

Some important limitations should be noted. The present study represents a single-center experience with a relatively small sample size which could be regarded as a limitation of the study. The study was not randomized. This is a potential limitation, however, it may provide a real-world description of a single center experience. However, the complete analysis of consecutive patients without any exclusion criteria and with follow-up data for all patients was performed.

\section{Conclusions}

Computed tomography-guided percutaneous femoral access in TAVI may provide comparable procedural outcomes compared to the SA, despite a higher radiation dose and the use of contrast dye, while being less invasive. It is necessary to emphasize the importance of the role of teamwork played between interventional cardiologist and cardiac surgeon in final decisions about optimal access based on CT assessment.

\section{Acknowledgments}

This article was supported by the science fund of the John Paul II Hospital, Krakow, Poland $\mathrm{FN} / 11 / 2021$.

\section{Conflict of interest: None declared}

\section{References}

1. Leon MB, Smith CR, Mack M, et al. PARTNER Trial Investigators. Transcatheter aortic-valve implantation for aortic stenosis in patients who cannot undergo surgery. N Engl J Med. 2010; 363(17): 1597-1607, doi: 10.1056/NEJMoa1008232, indexed in Pubmed: 20961243.

2. Parma R, Zembala MO, Dąbrowski M, et al. Transcatheter aortic valve implantation. Expert Consensus of the Association of Cardiovascular Interventions of the Polish Cardiac Society and the Polish Society of Cardio-Thoracic Surgeons, approved by the Board of the Polish Cardiac Society and National Consultants in Cardiology and Cardiac Surgery. Kardiol Pol. 2017; 75(9): 937-964, doi: 10.5603/KP.2017.0175, indexed in Pubmed: 28895996.

3. Biasco L, Ferrari E, Pedrazzini G, et al. Access sites for TAVI: patient selection criteria, technical aspects, and outcomes. Front Cardiovasc Med. 2018; 5: 88, doi: 10.3389/fcvm.2018.00088, indexed in Pubmed: 30065928.

4. Hecker F, Arsalan M, Kim W, et al. Transcatheter aortic valve implantation (TAVI) in 2018: recent advances and future development. Minerva Cardioangiol. 2018; 66(3): 314-328.

5. Dimitriadis Z, Scholtz W, Ensminger SM, et al. Impact of sheath diameter of different sheath types on vascular complications and mortality in transfemoral TAVI approaches using the Proglide closure device. PLoS One. 2017; 12(8): e0183658, doi: 10.1371/ journal.pone.0183658, indexed in Pubmed: 28837613.

6. Durmuş G, Belen E, Bayyiğit A, et al. Comparison of complication and success rates of proglide closure device in patients undergoing TAVI and endovascular aneurysm repair. Biomed Res Int. 2018; 2018: 2687862, doi: 10.1155/2018/2687862, indexed in Pubmed: 30175119.

7. Barbanti M, Capranzano P, Ohno Y, et al. Comparison of suturebased vascular closure devices in transfemoral transcatheter aortic valve implantation. EuroIntervention. 2015; 11(6): 690-697, doi: 10.4244/EIJV11I6A137, indexed in Pubmed: 26499222.

8. Biancari F, Romppanen H, Savontaus M, et al. MANTA versus ProGlide vascular closure devices in transfemoral transcatheter aortic valve implantation. Int J Cardiol. 2018; 263 : 29-31, doi: 10.1016/j.ijcard.2018.04.065, indexed in Pubmed: 29681408.

9. Hoffmann P, Al-Ani A, von Lueder T, et al. Access site complications after transfemoral aortic valve implantation: a comparison of Manta and ProGlide. CVIR Endovasc. 2018; 1(1): 20, doi: 10.1186/s42155-018-0026-0, indexed in Pubmed: 30652151. 
10. Barbash IM, Barbanti M, Webb J, et al. Comparison of vascular closure devices for access site closure after transfemoral aortic valve implantation. Eur Heart J. 2015; 36(47): 3370-3379, doi: 10.1093/eurheartj/ehv417, indexed in Pubmed: 26314688.

11. Moriyama N, Lindström L, Laine M. Propensity-matched comparison of vascular closure devices after transcatheter aortic valve replacement using MANTA versus ProGlide. EuroIntervention. 2019; 14(15): e1558-e1565, doi: 10.4244/EIJD-18-00769, indexed in Pubmed: 30295293.

12. Kappetein AP, Head SJ, Généreux P, et al. Updated standardized endpoint definitions for transcatheter aortic valve implantation: the Valve Academic Research Consortium-2 consensus document. J Am Coll Cardiol. 2012; 60(15): 1438-1454.

13. Stąpór M, Trębacz J, Wiewiórka $€$, et al. Direct left ventricular wire pacing during transcatheter aortic valve implantation. Kardiol Pol. 2020; 78(9): 882-888, doi: 10.33963/KP.15440, indexed in Pubmed: 32567288.

14. Kleczynski P, Dziewierz A, Socha S, et al. Direct rapid left ventricular wire pacing during balloon aortic valvuloplasty. J Clin Med. 2020; 9(4): 1017, doi: 10.3390/jcm9041017, indexed in Pubmed: 32260289.

15. Rockwood K, Song X, MacKnight C, et al. A global clinical measure of fitness and frailty in elderly people. CMAJ. 2005; 173(5): 489-495, doi: 10.1503/cmaj.050051, indexed in Pubmed: 16129869.

16. Walas RL, Kukulski L, Rychter J, et al. Vascular access site complications after transfemoral transcatheter aortic valve implantation in the POL-TAVI Registry: surgical versus percutaneous approach. J Cardiovasc Surg (Torino). 2020; 61(1): 117-122, doi: 10.23736/S0021-9509.19.11087-7, indexed in Pubmed: 31815374 .

17. Wiktorowicz A, Kleczynski P, Dziewierz A, et al. Impact of frailty on mortality after transcatheter aortic valve implantation. Am Heart J. 2017; 185(7): 52-58, doi: 10.1016/j.ahj.2016.12.005, indexed in Pubmed: 28267475.

18. Bernardi FLM, Gomes WF, de Brito FS, et al. Surgical cutdown versus percutaneous access in transfemoral transcatheter aortic valve implantation: Insights from the Brazilian TAVI registry. Catheter Cardiovasc Interv. 2015; 86(3): 501-505, doi: 10.1002/ ccd.25820, indexed in Pubmed: 25586633.

19. Karol Z, Grodecki K, Gozdowska R, et al. Use of protamine sulfate during transfemoral transcatheter aortic valve implantation: a preliminary assessment of administration rate and impact on complications. Advances in Interventional Cardiology. 2020; 16(3): 306 -314, doi: 10.5114/aic.2020.99266, indexed in Pubmed: 33597996.

20. Kochman J, Kołtowski $Ł$, Huczek Z, et al. Complete percutaneous approach versus surgical access in transfemoral transcatheter aortic valve implantation: results from a multicentre registry.
Kardiol Pol. 2018; 76(1): 202-208, doi: 10.5603/KP.a2017.0205, indexed in Pubmed: 29131296.

21. Drafts BC, Choi CH, Sangal K, et al. Comparison of outcomes with surgical cut-down versus percutaneous transfemoral transcatheter aortic valve replacement: TAVR transfemoral access comparisons between surgical cut-down and percutaneous approach. Catheter Cardiovasc Interv. 2018; 91(7): 1354-1362, doi: 10.1002/ccd.27377, indexed in Pubmed: 29024382.

22. Généreux P, Webb JG, Svensson LG, et al. PARTNER Trial Investigators. Vascular complications after transcatheter aortic valve replacement: insights from the PARTNER (Placement of AoRTic TraNscathetER Valve) trial. J Am Coll Cardiol. 2012; 60(12): 1043-1052, doi: 10.1016/j.jacc.2012.07.003, indexed in Pubmed: 22883632.

23. Tchetche D, de Biase C, Brochado B, et al. How to make the TAVI pathway more efficient. Interv Cardiol. 2019; 14(1): 31-33, doi: 10.15420/icr.2018.28.2, indexed in Pubmed: 30858889.

24. van Mourik MS, Geenen LME, Delewi R, et al. Predicting hospitalisation duration after transcatheter aortic valve implantation. Open Heart. 2017; 4(1): e000549, doi: 10.1136/ openhrt-2016-000549, indexed in Pubmed: 28674621.

25. Barbanti M, van Mourik MS, Spence MS, et al. Optimising patient discharge management after transfemoral transcatheter aortic valve implantation: the multicentre European FAST-TAVI trial. EuroIntervention. 2019; 15(2): 147-154, doi: 10.4244/EIJD-18-01197, indexed in Pubmed: 30777842.

26. Aldalati O, Keshavarzi F, Kaura A, et al. Factors associated with safe early discharge after transcatheter aortic valve implantation. Cardiol J. 2018; 25(1): 14-23, doi: 10.5603/CJ.a2017.0087, indexed in Pubmed: 28714522.

27. Mallikethi-Reddy S, Akintoye E, Telila T, et al. Transcatheter aortic valve implantation in the United States: Predictors of early hospital discharge. J Interv Cardiol. 2017; 30(2): 149-155, doi: 10.1111/joic.12373, indexed in Pubmed: 28247569.

28. Kedev S, Zafirovska B, Srbinovska-Kostovska E, et al. Minimalistic approach for transcatheter aortic valve implantation (TAVI): open vascular vs. fully percutaneous approach. Pril (Makedon Akad Nauk Umet Odd Med Nauki). 2019; 40(2): 5-14, doi: 10.2478/prilozi-2019-0009, indexed in Pubmed: 31605589.

29. Giordano A, Corcione N, Ferraro P, et al. Registro Italiano GISE sull'impianto di Valvola Aortica Percutanea (RISPEVA) Study Investigators. Comparison of ProGlide vs. Prostar in patients undergoing transcatheter aortic valve implantation. Minerva Cardioangiol. 2019; 67(6): 443-449, doi: 10.23736/S00264725.19.05071-0, indexed in Pubmed: 31670491.

30. Urbach J, Hou CR, Lesser JR, et al. Computed tomographic angiography-derived risk factors for vascular complications in percutaneous transfemoral transcatheter aortic valve implantation. Am J Cardiol. 2019; 124(1): 98-104, doi: 10.1016/j.amjcard.2019.03.043, indexed in Pubmed: 31029410. 